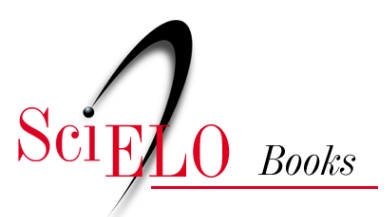

\title{
Um presumível ponto de partida
}

\author{
Eduardo Tudella
}

\section{SciELO Books / SciELO Livros / SciELO Libros}

TUDELLA, E. Um presumível ponto de partida. In: A luz na gênese do espetáculo [online]. Salvador: EDUFBA, 2017, pp. 115-132. ISBN: 978-85-232-1858-4.

https://doi.org/10.7476/9788523218584.0005.

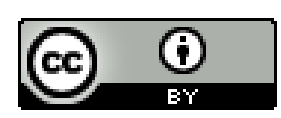

All the contents of this work, except where otherwise noted, is licensed under a Creative Commons Attribution $\underline{4.0 \text { International license. }}$

Todo o conteúdo deste trabalho, exceto quando houver ressalva, é publicado sob a licença Creative Commons Atribição 4.0.

Todo el contenido de esta obra, excepto donde se indique lo contrario, está bajo licencia de la licencia Creative Commons Reconocimento 4.0. 


\section{UM PRESUMÍVEL PONTO DE PARTIDA}

O capítulo que se inicia tentará estabelecer uma ligação entre Ésquilo e Shakespeare, observando o trato político e a familiaridade com o palco que os levava a escrever com o olhar projetado para a cena, encarada aqui como poderosa tentação para um dramaturgo. Assume-se, portanto, que a presença de tais feições no teatro de ambos indica certo grau de parentesco dramatúrgico entre eles.

A hipótese em questão leva à observação do teatro da Antiguidade, particularmente no século $V$ a.c., uma vez que lá podem ser identificados contatos particulares entre a luz e a práxis cênica. Torna-se necessário, então, refletir sobre as articulações operadas na cena, com o intuito de compreender sua qualidade visual, o que efetiva uma ação decisiva da luz, mesmo diante da 
situação limite na qual estava instalada a obra teatral da Antiguidade, ao produzir o seu espetáculo sob a luz do sol, reduzindo-se drasticamente as possibilidades de controle.

A investigação volta-se, então, para textos que provoquem discussões a respeito das mencionadas feições da luz nos espetáculos, observando a articulação de um raciocínio organizado acerca de suas contribuições. O primeiro documento destacado é a compilação de Ioulios Poludeukes ou Iullius Pollux (século II d.C.), Onomastikon, sem ignorar possíveis controvérsias, incluindo o questionamento da integridade ou validade do texto.

É preciso registrar que tais dúvidas e controvérsias devem ser estendidas a outras obras, sobre as quais existem incertezas, inclusive sobre sua autoria, seu estado incompleto e/ou fragmentado. Ainda assim, algumas dentre elas podem representar fontes únicas e valiosas para a pesquisa, em muitas áreas do conhecimento. No caso do texto de Pollux, há, segundo Nagler, claros indicadores de que ele trata do edifício teatral helenístico. Nagler (1952, p. 8, tradução nossa) salienta: "Não temos certeza se ele fala do teatro Helenístico ou daquele da era de Péricles, ainda que sua referência ao palco elevado indique, sem dúvida, que ele está discutindo as características do Teatro Helenístico".

De qualquer modo, mesmo considerando-se tal questionamento, é indispensável registrar a escassez de textos daquele momento e subsequentes, que discutam o edifício teatral grego, entre os anos 500 a.c. e o segundo século na presente era, momento no qual Pollux produziu seu trabalho, o que define sua importância para a pesquisa que apoia o presente trabalho. Mesmo que se possa questioná-lo, parece prudente observar sua consulta a relatos de estudiosos interessados no assunto, incluindo, segundo Nagler (1952), a Theatrical History escrita pelo Rei Juba II (52 a.c. - 23 d.C.). O Rei Juba II, da Numídia, escreveu diversos estudos, como corrobora Smith (1866, p. 636, tradução nossa):

Mas é por sua produção literária que Jubá [II] alcança mais importante reputação. Ele parece ter mantido, enquanto ocupava o trono, seus hábitos de estudo adquiridos desde jovem; o número e a variedade dos seus escritos podem ser comparados àqueles de muitos gramáticos reconhecidos. Seus trabalhos são frequentemente citados por Plínio (História Natural V. VIII. X. XII. XIII. \& C. passim), que lhe confere a mais alta deferência. [...] Ele parece ter trabalhado, sem dúvida, em quase todos

1 "We are not always sure whether he speaks of the theater of the Hellenistic or Periclean era, though his reference to the raised stage would indeed indicate that he is discussing the features of Hellenistic Theatre." 
os ramos da literatura: alguns dos seus trabalhos eram puramente voltados para a gramática ou para o estudo da antiguidade, enquanto que outros alcançam um vasto campo da história, geografia, história natural, e as belas artes. ${ }^{2}$

Smith (1866) menciona ainda um tratado do Rei Jubá II com, provavelmente, perto de duas dezenas de libri [capítulos], que tratam de todas as questões referentes ao teatro. Certos aspectos da descrição apresentada por Pollux constituem elementos importantes para o pensamento que se procura desenvolver no presente estágio deste trabalho. Em nenhum momento, o autor romano menciona a aplicação de luz artificial para promover visibilidade. A tradução inglesa, tendo como referência Nagler, traz apenas duas indicações de luz, em expressões muito particulares. A primeira delas é a expressão light-house ou farol, cujo posicionamento, função e aparência, não são explicitados e, mais tarde, encontra-se lightning-tower, "torre de relâmpago", descrita como um periaktos (elemento do dispositivo cenográfico usado no teatro grego antigo, de base triangular) com elevada dimensão vertical (Figura 9). Ambas as expressões trazem vestígios de ligações com a luz sem, contudo, considerar questões de iluminância (fluxo luminoso ou quantidade de luz que alcança ou chega a determinado ponto/objeto) do objeto descrito, pois o que se aplica à cena é uma representação pictórica, convencional, de um objeto encontrado no cotidiano, fora do espetáculo. Exclui-se, portanto, a expectativa da projeção de luz artificial sobre a cena, com a função específica de iluminar, de tornar visível. Por outro lado, os mencionados elementos da arquitetura cênica revelam, para o público, uma espécie de luz metafórica, simbólica, contribuindo para a visualidade do espetáculo.

Tal procedimento pode ser reconhecido como um aspecto muito particular que integrava as sofisticadas convenções do teatro na Grécia clássica, caracterizando as singularidades daquela práxis cênica. Nela se estabeleceu uma estreita relação entre a ação e o seu espaço, estimulando progressivas mudanças, ao longo dos séculos V e IV a.c., para efetivar um diálogo entre a poesia trágica e a cena para a qual ela foi concebida. Estava criado na civilização do Ocidente o termo teatro, assim como suas derivações, nomeando a atividade de natureza cênica. O entendimento moderno de teatro origina-se na palavra theatron ( $\theta \varepsilon \dot{\varepsilon} \alpha \tau \rho v)$, do grego antigo.

\footnotetext{
2 "But it is to his literary works that Juba is indebted for his chief reputation. He appears to have retained on the throne the habits of study which he had acquired in early life; and in the number and variety of his writings he might vie with many professed grammarians. His works are continually cited by Pliny (H. N. v. viii. x. xii. xiii. e passim), who regards his authority with the utmost deference [...]. He appears indeed to have laboured in almost every branch of literature; some of his works being purely grammatical or antiquarian, while others comprise a wide field of history, geography, natural history, and the fine arts."
} 
Thea $(\theta \varepsilon \dot{\varepsilon} \mathrm{\mu} \alpha \mathrm{l})$, indicando ver, assistir, enquanto que theatron refere-se ao "lugar de onde se vê" ou "o que se vê", relacionando-se tanto ao espaço que acomodava os espectadores, quanto ao público em si, o conjunto de espectadores presentes ao evento. Theatron ( $\theta \varepsilon \dot{\varepsilon} \alpha \rho \rho v)$ é um substantivo derivado da ação de ver, olhar, contemplar, observar $(\theta \dot{\varepsilon}$ o $\mu \alpha)$ ). A arte teatral, portanto, encontra-se visceralmente enraizada num contexto visual, repercutindo a energia que alimenta o planeta, incluindo a luz visível originada pelo Sol.

Do theatron grego, o espectador poderia vislumbrar tanto a orchestra (ou lugar onde se dança), como espaço de atuação do coro, assim como a skéné, cuja utilização revelava a hierarquia social apresentada na tragédia. A porta central estava reservada para o trânsito das personagens de maior distinção nas relações sociais instituídas, e era acompanhada de duas portas menores, uma a cada lado. Tratava-se de uma configuração presente em um estágio avançado, no espaço do teatro da Grécia da Antiguidade, e, para citar um exemplo, basta destacar a mudança radical da orchestra, na arquitetura teatral romana, em relação à sua forma no período grego (Figuras 10 e 11). No período em questão, aliás, foram acrescentadas mais duas portas, dispostas nas paredes laterais da skéné que, mantidas na Roma Antiga, reapareceriam no Teatro Olímpico, em Vicenza, no século XVI.

Acentue-se, por outro lado, o valioso trabalho de Marcus Vitruvius Pollio, arquiteto/engenheiro romano, autor de De Architectura (ca. 80/70 a.c. - 15 a.c., 9o-20 a.c.), que trata da arquitetura teatral romana do século I, e repercutiria no Renascimento, para depois influenciar todo o teatro moderno.

Quando se usa o termo audiência, compreende-se a relação com auditorium, do latim audire (ouvir), numa alusão ao resgate da arquitetura romana antiga, provavelmente a partir dos estudos de Vitruvius. Em De Architectura Libri X, ele diz:

2. Como resultado desta planta com três centros os gregos têm uma orchestra mais espaçosa e uma 'scaena' disposta mais ao fundo, assim como um palco de menor profundidade. Eles o

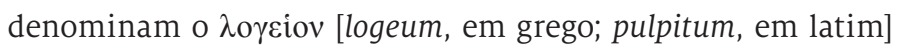
porque os atores trágicos e cômicos ocupavam o palco enquanto que outros artistas desempenhavam suas funções por toda a orchestra; a partir de então, eles receberam, em grego, os nomes distintos 'Cênicos' e 'Thimélicos'. O pé-direito do 'logeum' não deveria ser menor do que três metros nem maior do que três metros e sessenta centímetros. ${ }^{3}$ (VITRUVIUS, 1914, p. 151, tradução nossa)

3 'As a result of this plan with three centers, the Greeks have a roomier orchestra, and a 'scaena' set further back, as well as a stage of less depth. They call this the $\lambda$ o $\gamma \varepsilon$ iov for the reason that there the tragic and comic actors 
Isso demonstra como o teatro grego daquele tempo se instalou em um contexto no qual a percepção visual representava aspecto de grande relevância. Uma vez que a função do coro grego, como elemento essencial na convenção da poesia trágica desaparece no teatro romano, a orchestra se modifica para atender às suas novas proposições.

\section{A LUZ COMO DESTINO DA POESIA TRÁGICA}

Se o espetáculo era apresentado sob a luz do Sol e as imagens da cena exigiam atmosfera diversificada daquela expressa no tempo e no lugar onde o evento efetivamente ocorria, o artista criava soluções, para construir a visualidade que tornaria a cena possível. o oxford companion to the theatre, organizado por Phillys Hartnoll, avança numa direção crucial, quando diz:

Para lidar com a história da luz para a cena é necessário distinguir entre a iluminação artificial do teatro e o uso de luzes no palco. [...] Em todos os períodos, velas, tochas, lamparinas e lampiões foram usados como adereços de cenografia para indicar noite ou escuridão. ${ }^{4}$ (HARTNOLL, 1957, p. 461)

Ele chama a atenção para a inexistência da necessidade de luz artificial, com o objetivo de garantir visibilidade à cena, tanto na Grécia quanto em Roma; até mesmo nos palcos móveis, ao ar livre, do teatro religioso medieval, assim como na cena elisabetana e jacobina, com os seus teatros sem cobertura. Como já foi dito antes, na referência a Shakespeare, é possível especular acerca da necessidade de luz artificial para corrigir a reduzida visibilidade num fim de tarde, durante o outono londrino. Ao trabalho em curso, contudo, importa retornar ao teatro grego clássico, com o intuito de observar suas prováveis relações com a luz, desde sua gênese na dramaturgia. Para tanto, vale introduzir a definição de Aristóteles (384 a.c. - 322 a.c.), para a tragédia. Diz ele: "A tragédia, então, é um processo de

perform on the stage, while other artists give their performances in the entire orchestra; hence, from this fact they are given in Greek the distinct names 'Scenic' and 'Thymelic'. The height of this 'logeum' ought to be not less than ten feet nor more than twelve."

4 "In dealing with the story of stage lighting, it is necessary to distinguish between the artificial illumination of the theatre and the use of lights on the stage. [...] In all periods candles, torches, lamps, and lanterns have been used as stage properties to indicate night and darkness." 
imitação [mimese] de uma ação [não de homens] [...]; encenada efetivamente por pessoas e não apresentada através de narração". ${ }^{5}$ (ARISTÓTELES, 1983, p. 25)

Sublinhe-se a mimese de ações para apresentar uma compreensão da dramaturgia grega como obra concebida para se efetivar no espetáculo (opsis). A ponderação de Aristóteles delineia a contribuição da ação cênica, para a efetivação da tragédia: "Agora, antes de tudo, uma vez que eles elaboram a imitação através da ação, a ornamentação da sua aparência visual constitui alguma parte da tragédia; assim como a música e a expressão verbal, pois esses são os meios através dos quais eles efetivam a tragédia ${ }^{6}$ (ARISTÓTELES, 1983, p. 26)

Problematizando, pode-se considerar que, desde Aristóteles, a presença do espetáculo para a completude da tragédia, na sua condição de forma artística, sugere discussões. É possível argumentar que, para Aristóteles, a poesia trágica, a palavra, apresenta hegemonia em relação ao opsis, autossuficiência como obra de arte, capaz de efetivar a função catártica, dispensando a práxis cênica e concentrando o propósito de expressar as ideias na palavra em si, no processo da elocução. Na última citação acima, entretanto, cabe observar a particularidade do pensamento teatral ao qual Aristóteles se refere.

No século XXI, o espetáculo cênico (opsis), pode ser encarado de maneiras diversificadas, inclusive como um conjunto de fragmentos sem compromisso com a unidade. Naquilo que os gregos clássicos denominaram teatro, contudo, a poesia era elaborada para ser representada numa cena norteada pelos princípios da unidade, ela era gerada para se completar como forma artística na realização cênica, no espetáculo. No que se refere ao espetáculo trágico, portanto, também a música e a elocução representavam procedimentos pensados pelo poeta, e planejados para o momento da corporificação no espetáculo. A abordagem da cena, na sua condição de "corpo", aparece no trabalho de Patrice Pavis (2005, p. 139):

Poderia se esperar que o espaço, a ação e o tempo sejam os elementos mais tangíveis do espetáculo, mas a dificuldade consiste não em descrevê-los separadamente, mas em observar sua interação. Um não existe sem os outros dois, pois o espaço/tempo dramatúrgico, o trinômio espaço-tempo-ação, forma um só corpo atraindo para si, como que por imantação, o resto da representação. Ele se situa, além dis-

\footnotetext{
5 "Tragedy, then, is a process of imitating an action [...]; enacted by the persons themselves and not presented through narrative."

6 "Now first of all, since they perform the imitation through action (by acting it) the adornment of their visual appearance will perforce constitute some part of the making of tragedy; and song- composition and verbal expression also, for those are the media in which they perform the imitation."
} 
so, na intersecção do mundo concreto da cena (como materialidade) e da ficção imaginada como mundo possível. Constitui um mundo concreto e um mundo possível no qual se misturam todos os elementos visuais, sonoros e textuais da cena.

É importante esclarecer que a expressão cena-corpo é aqui compreendida de modo diferenciado daquela usada por Pavis (2005), quando ele menciona o trinômio espaço-tempo-ação. Os elementos que ele chama de "resto" da representação são compreendidos, no presente trabalho, como elementos constitutivos do corpo denominado acontecimento espetacular. Não há, portanto, um resto da representação que é por ela atraído, pensamento do qual Pavis se aproxima quando, mais tarde, no mesmo texto, aplica a expressão "os outros elementos materiais da representação". (PAVIS, 2005, p. 168-184) Qualquer aspecto da práxis cênica é parte orgânica de um corpo constituído de espaço-tempo-ação. Cada um desses aspectos tem funções diferenciadas, mas cada um deles se encontra organicamente incorporado à constituição da cena. Isso é característica fundamental do espetáculo: o mundo concreto da cena, o ambiente no qual ela se revela e se manifesta como corpo, não aceita a imposição de elementos que constituiriam o tal "resto" da representação. Ou seja, qualquer aspecto da cena estará inserido em uma das categorias mencionadas por Pavis - visual, sonora ou textual - tendo, portanto, função particular no organismo, na fisicalização do corpo cênico, identificado por Pavis pelo trinômio espaço-tempo-ação.

Por outro lado, pode-se considerar que cada instância particular do espetáculo - cenografia, dramaturgia, luz, música, figurinos, direção, maquiagem, interpretação - conduz um discurso autônomo e, simultaneamente, conectado a uma ideia catalisadora que provoca a práxis cênica, mesmo que se esteja tratando de proposições espetaculares que desprezam a definição de um sentido prévio e invistam no processo - ou relação - entre o acontecimento espetacular e o fruidor. Daí, o alto grau de dificuldade encontrado na realização de um espetáculo, ou seja, a interação de múltiplos discursos autônomos num só objeto artístico. Note-se a proposição do teatro performativo, observando-se a ponderação de Josette Féral (2008, p. 209, grifo nosso): ${ }^{7}$

Uma das principais características desse teatro é que ele coloca em jogo o processo sendo feito, processo esse que tem maior importância do que a produção final. Mesmo que essa seja meticu-

7 Professora da Universidade do Quebéc. 
losamente programada e ritmada, assim como na performance, o desenrolar da ação e a experiência que ela traz por parte do espectador são bem mais importantes do que o resultado final obtido.

Essa produção final, que na tragédia grega era também programada e ritmada para atender a objetivos específicos, o terror e a piedade, constituía o opsis. Ambos os exemplos investiram na excelência da visualidade, cada um no seu tempo e norteado por desejos particulares. No caso do teatro performativo, espera-se uma intervenção da luz meticulosamente concebida.

A cena grega será aqui retomada com a Medeia de Eurípedes, abordando a elocução particular da qual a poesia dramática estava impregnada. Quando o Mensageiro sai do interior da skéné e descreve o envenenamento da jovem Glauce, o espectador devia ser surpreendido através de uma métrica precisamente definida, que expressa o horror da visão. Uma acentuação equivocada na poesia poderia distanciar o espetáculo dos propósitos definidos pela dramaturgia de Eurípedes. É preciso imaginar o momento, a primeira fala, antes de quaisquer detalhes fornecidos pelo servo de Jasão, para construir o quadro de pavor testemunhado no interior do palácio.

Entra o Mensageiro, vindo do palácio real - | MENSAGEIRO | [...] Ela, então, levantou-se de seu | assento e caminhou | até o outro lado do aposento, movendo-se delicadamente | sobre seus pés pálidos, encantada com os presentes | inspecionando cuidadosamente | a justeza do vestido nas suas pernas | Mas então aconteceu - uma horrível visão. | [...] Ela mudou de cor, cambaleou para trás e para os lados, | tremendo e, em seguida, jogou-se em sua cadeira, | quase caindo no chão. | [...] uma espuma branca lhe saia da boca, seus olhos | estavam inchados em suas órbitas, e sua pele pálida | completamente sem sangue. | [...] Ela sofria uma dupla agonia - o diadema de ouro em torno de sua cabeça | derramava incríveis fluxos de fogo derretido | queimando tudo e o rico manto | presente dos seus filhos consumia a carne da pobre jovem. | Ela pulou da cadeira e correu para longe, | fogo por todo o corpo, sacudindo a cabeça, os cabelos, | tentando livrar-se da sua coroa dourada - mas ela estava presa e, | quando a jovem sacudia os cabelos, o fogo ardia | duas vezes mais. Em seguida, ela caiu no chão, | abatida pela desgraça. Ninguém a reconheceria, exceto seu pai. | Seus olhos perderam sua límpida expressão, | sua face transformou-se. E havia sangue | sobre sua cabeça, escorrendo, misturado ao fogo. | Sua pele saía dos ossos, carcomida | Pelas mandíbulas 
secretas do veneno, [...] | Uma visão pavorosa! ${ }^{8}$ (EURÍPEDES, 2008, p. 1368-1414, tradução nossa)

Ainda que diante do texto cada leitor possa alcançar experiências diversificadas na relação direta entre o seu próprio imaginário e leitura, o estudo da métrica na tragédia clássica grega representa uma disciplina. No caso particular da poesia de Eurípedes, quando um ator, treinado segundo aquelas convenções, partilhava com um diretor as singularidades da obra, a cena podia efetivar a métrica planejada pelo poeta, para encaminhar determinadas emoções, de acordo com os desejos e conflitos que geraram a ação.

Não é difícil imaginar o grau de dificuldade que o espectador mais afastado da skéné enfrentaria, ao buscar detalhes de visibilidade naqueles espetáculos realizados em teatros com capacidade para abrigar milhares de pessoas, por vezes mais de uma dezena de milhares, como é o caso de Epidaurus. Parece, portanto, que do ator grego da Antiguidade eram esperados gestos muito largos, aliados à elocução competente. Os homens precisavam falar bem e, principalmente, deveriam ser capazes de executar a métrica particular de cada momento. O poeta incluía qualidade musical - ritmo, andamento e melodia - na ação trágica, uma melopeia que se efetivava em parceria com uma abordagem visual particular. O ator, cuja esta-

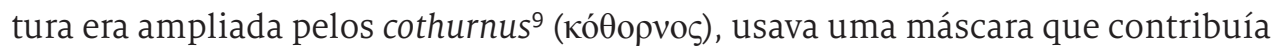
para uma caracterização estritamente ligada a convenções muito específicas, que impulsionavam aquela poesia para a cena, cena na sua condição de corpo transitório, dinâmico, sempre inacabado, mas não por isso destituído de planejamento (Figura 12).

8 " $[. .$.$] Then she stood up from her seat and strolled | across the room, moving delicately \mid$ on her pale feet, delighted with the gifts, | with a great many glances to inspect | the straightness of the dress against her legs. | But then it happened - a horrific sight. | [...] She changed colour, staggered back and sideways, | trembling, then fell into her chair again, | almost collapsing on the floor. | [...] the white spit foaming in her mouth, her eyes | bulging from their sockets, and her pale skin | quite drained of blood. | [...] She was suffering a double agony - | around her head the golden diadem | shot out amazing molten streams of fire | burning everything, and the fine woven robe, | your children's gift, consumed the poor girl's flesh. | She jumped up from the chair and ran away, | all of her on fire, tossing her head, her hair, | this way and that, trying to shake off | her golden crown - but it was fixed in place, | and when she shook her hair, the fire blazed | twice as high. Then she fell down on the ground, | overcome by the disaster. No one | could recognize her, except her father. | Her eyes had lost their clear expression, | her face had changed. And there was blood | on top her head, dripping down, mixed with fire. | The flesh was peeling from her bones, chewed off | by the poison's secret jaws, [...]. | An appalling sight!"

9 Uma bota. Sua distinção essencial era a sua altura, alcançando o meio da perna, de modo a envolver a panturrilha, às vezes chegando até os joelhos. Foi usada principalmente pelos cavaleiros, caçadores, e por homens de posição e autoridade. Os atores da tragédia ateniense assumiram o uso de um coturno com solas muito espessas, como um dos métodos adotados para ampliar sua figura. (VIRGÍLILO; HORÁCIO apud SMITH, 1870, p. 336) 
Na atualidade brasileira, quando se entende "encenação" como forma artística autônoma que toma quaisquer parâmetros que a antecedam como provocações e até desconsidera qualquer indício de poesia dramática, observações de tal natureza podem indicar o obsoleto. O que é aqui acentuado, contudo, é a opção disponível para um diretor familiarizado com tais aspectos. O que deve ser necessariamente mencionado é a consciência que o artista grego tinha da importância das imagens visuais para a cena, como se pode observar na decisão de evitar ocorrências violentas na cena propriamente dita, precisamente porque essa qualidade de visões incorporaria ao espetáculo imagens que - na compreensão daqueles artistas - eram consideradas inapropriadas.

Ao espectador era revelado um resultado visual de ações, o que gerou um elemento determinante para a convenção dramatúrgico-cênica. É possível supor que a cena grega enfrentava a criação das atmosferas propostas pela poesia trágica num espetáculo cruamente exposto pela luz do sol, como um problema do teatro. Caminhar ou não, na direção proposta pela poesia, é uma escolha que pode ser definida pela compreensão de suas potencialidades. Construir uma cena que desconsidere as premissas propostas por uma dramaturgia de tal natureza, que tem na sua gênese a cena como destino, é uma séria decisão exigindo fundamentação consistente.

Aquele que se interessa pela imagem cênica pode projetar na mente a qualidade do espetáculo grego, construído com unidades visuais impregnadas de movimentos muito particularmente concebidos, segundo convenções amadurecidas através da experimentação,incluindo contexto sonoro específico. É possível, portanto, inferir que aqueles artistas desenvolveram habilidade para incorporar as condições de visualidade oferecidas pela luz solar. Retornando ao contexto de Medeia, ainda que se possa dizer que o espectador de Eurípedes detinha familiaridade com a narrativa de Argos, cuja popularidade só era menor que a da saga de Troia, o espetáculo grego se constituía da expressão de uma narrativa poética na qual o termo ação é aqui compreendido como uma relação exemplar: uma parceria entre a ação dramática inscrita na poesia e uma atividade cênica - voz, gestos e movimentos do ator na cena propriamente dita - impregnada de determinadas convenções, inclusive espaciais, resultando em espetacularidade particular.

As possibilidades de interpretação da Poética aristotélica passam, então, na presente abordagem, pelo entendimento de uma poesia cujo destino é a cena. Na abertura do capítulo XIV dessa obra, lê-se:

É possível provocar o terror e a piedade através da aparição dos atores, mas é também possível que eles sejam provocados pela 
estruturação dos acontecimentos, e esta é a marca do melhor poeta. Ou seja, a fábula deve ser tão estruturada que, mesmo sem o uso de qualquer efeito visual aquele que estiver ouvindo o relato dos eventos estremeça e se apiede, pois é o que acontece com aquele que ouve a fábula de Édipo. Procurar o alcance dessas emoções através do uso de máscaras e figurinos é menos artístico e requer suporte técnico no espetáculo, [...]..$^{10}$ (ARISTÓTELES, 1983, p. 40, tradução nossa)

O que está em discussão é o jogo de hegemonias; as máscaras e os figurinos, assim como a técnica exigida para sua eficácia em cena, parecem assustar Aristóteles. Parece claro que promover a relação entre tais elementos, no contexto da poesia trágica, é conditio sine qua non para o poeta que escreve vendo a cena como estágio do processo. Atingir os objetivos da tragédia por meio do acontecimento cênico, entretanto, é a primeira possibilidade por ele mencionada, apontando-a como outra instância expressiva da manifestação trágica, que atraía milhares de membros da comunidade para a única experiência estética imediata, presencial, que a humanidade pôde realizar até hoje, ou seja: discutir, experimentar emoções, contemplar e avaliar sua própria condição e relações, numa realização que congregava artista e público, nas condições mencionadas acima, a práxis cênica. O comentário a seguir, apresentado por Fernando M. Gazoni (2006, p. 28, grifo nosso), acentua as relações entre opsis e mimesis:

A melodia é classificada como um hedusma, palavra traduzida como 'ornamento', mas que tem a mesma raiz de 'prazer' e seria vertida mais propriamente como 'tempero'. A ela cabe, na Poética, um destino similar ao do espetáculo. O prazer que ela proporciona, assim como o prazer ligado a efeitos cênicos, deve dar lugar ao prazer próprio da tragédia, aquele que provoca o medo e a piedade por meio da mimese, e que deve estar ligado às ações.

Tratando do medo e da piedade gerados pela mimesis de uma ação completa, acentuando a ação, pode-se considerar que a poesia é suficiente para, e capaz de cumprir a função trágica, prescindindo de hedusmas, no sentido de ornamentos.

\footnotetext{
10 "Now it is possible for the fearful or pathetic effect to come from the actors' appearance, but it is also possible for it to arise from the very structure of the events, and this is closer to the mark and characteristic of a better poet. Namely, the plot must be so structured, even without benefit of any visual effect, that the one that the one / who is hearing the events unroll shudders with fear and feels pity at what happens: which is what one would experience on hearing the plot of the Oedipus. To set out to achieve this by the means of the masks and costumes is less artistic, and requires technical support in the staging."
} 
O opsis poderia ser considerado um ornamento e, portanto, desnecessário. Ele estaria sendo equiparado a "efeitos" como aqueles mencionados por Pollux (apud NAGLER, 1952, p. 9, tradução nossa): "A torre de relâmpago e trovão eram, respectivamente, um periaktos de grande dimensão vertical, e sacos cheios de seixos colocados atrás da skéné, que eram despejados em vasos de bronze"."1 E ainda poderiam ser listados separadamente, como itens isolados, a melodia, o opsis, assim como outros "efeitos". Estariam sendo questionados aspectos considerados dispensáveis, exageros em “ornamentação", e não a cena, não a mimesis em si, da ação humana, já que ela seria indispensável para que se efetivasse a representação trágica, para a comunidade.

É possível inferir que, no entendimento de Aristóteles, tal "tempero" era menos importante que a ação humana em busca da felicidade e, assim, a tragédia cumpriria sua função, já na poesia, na palavra lida e/ou também, ouvida. Por outro lado, o crítico Aristóteles poderia estar desaprovando excessos "espetaculosos" e, portanto, desnecessários. Tais considerações podem sugerir uma articulação da cena, anunciando aquilo que no teatro brasileiro do século XX se denominaria "encenação".

Um enfoque atual pode suscitar comentários acerca da hegemonia da palavra usando o rótulo de visão texto-centrista; e ainda, o interessado no reconhecimento do espetáculo como obra autônoma, discordaria em muitos pontos, afirmando mesmo que a melopeia, como exemplo, não pode ser considerada mero "tempero" ou ornamento. Até mesmo certos "efeitos" - como o ruído dos trovões, mencionado acima - se forem levadas em conta as características do espaço teatral em que era realizada a cena da Grécia Antiga, podem ser considerados aspectos inerentes e perfeitamente incorporados a determinado espetáculo. Cabe lembrar que mesmo na compreensão brasileira da função de "encenador", ele provoca, sugere caminhos para a realização do espetáculo e precisa contar com a conjunção resultante das realizações de diversos artistas que articulam a corporificação da cena. Desde os atores, podendo-se incluir um dramaturgo, um músico, além dos autores da proposição visual, seja um cenógrafo, um figurinista, e até um iluminador, membro mais recente no grupo de artistas envolvidos, entre outros. Um espetáculo sugere, portanto, uma espécie de conjunção que integra certa diversidade de práticas, com o intuito de "fisicalizar"12 ideias num corpo expressivo.

\footnotetext{
11 "The lightning-tower and thunder were, the former a high periaktos, and the other backwards under the skené, bags full of pebble-stones poured into a brazen vessel."

12 Sem ligação com o fisicalismo de Rudolf Carnap (1891-1970), e sua incursão no positivismo lógico, "[...] teoria segundo a qual os diversos campos do conhecimento, inclusive as chamadas ciências humanas, devem elevar a
} 
Valho-me da poesia de Ésquilo (ca. 525/524 a.c.-456/455 a.c.), uma vez que ela oferece elementos determinantes para as reflexões sobre o trinômio texto-visuali-

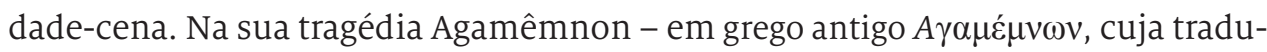
ção pode até aproximar-se de impulsivo - que abre a trilogia Oréstia (cuja primeira representação se deu em 458 a.c., em Atenas), o arranjo dos fatos elaborado pelo autor abre a instalação da fábula, com a intervenção de uma única personagem na skéné. Mesmo levando-se em conta a proximidade do público com o mythos, cabe indagar por que o poeta começaria sua tragédia com uma personagem considerada secundária na escala social abordada em sua trilogia, cujo tema revela conflitos que envolvem reis e rainhas. Parta-se de uma abordagem que aceita Ésquilo como artista profundamente envolvido na cena, tendo transitado desde o papel de autor da poesia trágica até aquele de ator em cena, assumindo também a posição de responsável pela organização do espetáculo.

Além disso, ainda que se considere o corifeu um ator, mesmo enquanto ele toma parte do coro, como líder, pode-se dizer que Ésquilo criou também a figura do ator, na sua posição de artista e profissional. Melhor dizendo: quando ele introduziu um ator, além do corifeu, o segundo ator que dividiria os papéis com o primeiro ator - também autor e até diretor - Ésquilo estaria inventando a figura própria do ator, como aquele cuja função é interpretar papéis. Ele não é o corifeu que lidera um grupo e assume falas mais importantes, tampouco é um autor que faz os papéis por razões diversas - por exemplo, porque são os mais importantes ou porque são os mais difíceis e ele os conhece bem, uma vez que os elaborou. Ésquilo introduziu o específico profissional cuja função especializada é interpretar papéis.

Em Agamêmnon, a ação se inicia quando uma Sentinela postada na cobertura do Palácio dos Atridas, casa de Agamêmnon, relata a espera por um sinal de fogo que se originará numa distante montanha, revelando a queda de Troia, e o consequente retorno do herói. Após longa e dolorosa espera, a Sentinela anuncia, cantando e dançando para o povo de Argos, a vitória do seu rei, configurando-se uma espécie de "rotina vazia". É preciso dizer que as trevas noturnas, já descritas na poesia de Ésquilo, serão reinventadas na imaginação do espectador, no momento mesmo de cada espetáculo.

física à condição de um paradigma científico universal, supondo que todos os aspectos da realidade, inclusive estados mentais e afetivos, somente adquirem plena compreensibilidade e concretude se analisados como realidades físicas". (HOUAISS, 2009) 
De modo simples e engenhoso, o poeta propõe (na introdução monológica do prólogo) um diálogo com o imaginário do espectador, compartilhando com ele o ambiente sombrio da prolongada espera noturna.

Deve-se observar a gravidade da situação política da qual trata o mito, reconhecido pelo espectador de Ésquilo. O tão esperado anúncio luminoso foi arquitetado por Clitemnestra, que planejou se preparar para a chegada do marido. Lembre-se que, em algumas versões do mito, Agamêmnon havia sacrificado a própria filha Ifigênia, para apaziguar ira da deusa Artemísia, e, por conseguinte, ter vento para velejar em direção à batalha. Quando, anos depois, Agamêmnon parte para a guerra de Troia, deixando sua mulher Clitemnestra, que se torna amante de Egisto - assassino de Atreu, pai do seu marido, e de quem Egisto era sobrinho - com o argumento da garantia de equilíbrio político e de paz. O retorno de Agamêmnon representa, portanto, uma ameaça de conflito político, e aponta para uma guerra civil. Numa história de profundos traumas, deve-se acentuar que, mesmo antes do episódio da guerra de Troia, o pai de Agamêmnon, Atreu, assassinou os filhos do seu irmão gêmeo Tiestes e serviu em banquete a carne de ambos para o próprio pai. A tragédia era levada à cena para um público familiarizado com a narrativa mítica.

No que se refere à atmosfera criada por Ésquilo, a personagem deixa de ser uma mera "sentinela", deixa de ser mais uma figura em cena. Não se trata de alguém com baixa posição na pirâmide representativa do modelo social vigente, mas um aspecto determinante da poesia dramática e da instalação do opsis. A Sentinela anuncia:

Aqui no alto do palácio dos Atridas | aos deuses todos peço há muitos, longos anos que me liberem da vigília cansativa. | Firmado em meu braço dobrado, sempre atento, | igual ao cão fiel, de tanto olhar o céu | noite após noite agora sei reconhecer | a multidão inumerável das estrelas, | senhoras lúcidas do firmamento etéreo, | indicadoras dos invernos e verões | em seu giro constante pela imensidão. | Espreito a todo instante o fogo sinaleiro | que nos dará notícia da queda de Tróia; | são ordens da mulher de ânimo viril, | rainha nossa, persistente na esperança. (ÉSQUILO, 1990, p. 19, grifo nosso)

Os grifos incluídos na tradução delineiam o cerne da discussão: a noite, elaborada em um espetáculo realizado em plena luz do dia - como ocorria naquele período - através da contundência da dramaturgia de Ésquilo, acentua a confiança do poeta na força da palavra. A poesia incorpora relações vitais do ser humano 
com a luz, relações capazes de projetar uma parceria vigorosa, que promoveria, na imaginação do público, uma expressiva efetivação da ação trágica mergulhada numa densa atmosfera noturna. Parece quase óbvia a afirmação visual do ambiente da ação, imerso numa interminável e angustiante espera que torna difícil imaginar a Sentinela sob um luar romântico, confortável. A imagem instalada por Ésquilo indica frieza, dureza, aspereza, desconforto. A atmosfera já se encontra na poesia, e aquele que se deixa provocar pela obra, aventurando-se no empreendimento de fisicalizá-la como corpo-cena, terá uma tarefa hercúlea: decidir entre propor em cena a mencionada atmosfera ou construir argumentos para negar sua validade como índice relevante para a discussão encaminhada pelo autor, trilhando outros caminhos.

Gösta M. Bergman (1977, p. 28), observando o momento no qual a tragédia antiga foi representada, comenta que os edifícios teatrais onde ocorriam os espetáculos da Grécia Clássica eram espaços sem cobertura, o que poderia expor muitos dos eventos ao escaldante calor da luz do sol, considerando que a apresentação de uma tetralogia (três tragédias e um drama satírico do mesmo autor) ou, mais tarde, uma tragédia de cada autor envolvido no festival, mais uma comédia, era programada para ocorrer ao longo do dia, gerando um acontecimento teatral que se estendia, provavelmente, até o crepúsculo.

Daí, é possível inferir que as diferenças de luminosidade apresentadas em um dia inteiro de atividades devem ter sido incorporadas pelos responsáveis pela cena, aplicando elaborações estéticas, buscando construir atmosferas.

Pode-se questionar a apresentação de uma trilogia em um único dia, argumentando que seriam necessárias mais de seis horas, e que a apresentação de uma tragédia e uma comédia coloca bem a moldura do tempo disponível em uma tarde. E ainda se pode questionar a possibilidade do próprio Ésquilo, como ator de várias "máscaras", atuar em três tragédias no mesmo dia. Sendo apresentada uma tragédia a cada dia, qual seria a ordem de apresentação? Observando que a tragédia como o momento mais importante do evento, ela seria encenada depois da comédia? Ou ao contrário, a comédia serviria como uma espécie de alívio para o público?

Considere-se que a atmosfera encaminhada na abertura da tragédia exige efetivação cênica contundente, capaz de abrir as portas do espetáculo para um público de milhares de espectadores. Em Agamêmnon, a noite representa para a Sentinela dolorosa vigília e as trevas noturnas são imprescindíveis para a revelação do sinal emitido ao longe: uma chama que se insinuará no escuro véu, povoado por incontáveis corpos celestes distantes, e até mortos, anunciando 
a vitória e, consequentemente, o fim da longa espera. Mais adiante, na mesma fala, e após uma pausa mencionada em publicações modernas (provocada pela dramaturgia que, quando apresenta a qualidade da poesia em questão, pode indicar aquilo que não se escutará, indicando silêncio vocal), ouve-se sua exclamação de júbilo:

É o sinal! É o sinal! Meus próprios olhos veem!| Eis a noturna luz que mudará decerto | a treva [...].

[...] e a mensagem da chama vista de tão longe | é o lance mais feliz de toda a minha vida! (ÉSQUILO, 1990, p. 20, grifo nosso)

A longa espera transforma-se em dúbia alegria, ou talvez fosse melhor dizer que os sinais de fogo produzem grande alívio, pois a mensagem de luz que revela o fim da guerra e o consequente retorno do rei proverá aos líderes tempo para que reflitam com o intuito de avaliar tensões políticas. A celebração que ocorre depois do anúncio da Sentinela, incluindo o desfile de archotes, as luzes dos altares, fortalece o traço de união entre a luz, os desejos e a situação dramática em curso.

Num certo sentido, bom seria tomar conhecimento da morte de Agamêmnon, uma vez que tal notícia já resolveria parte do problema. Clitemnestra, agora no poder, soberana, mãe e amante, tem diante de si a função de articular e conter a crise política que poderá se abater sobre o país. Se assassinando o próprio marido, Clitemnestra não evita e até precipita os fatos que se desenrolarão num novo anoitecer, a dramaturgia de Ésquilo mergulha em sombras profundas um mundo que se vê tomado pelas trevas. A poesia, então, constrói um ambiente particularmente diversificado do momento físico no qual o opsis ocorre, ou seja, durante o dia.

Se, em muitos casos, a noite é temida como um momento de trevas e terror, ao responder aos anseios do Corifeu, que se apresenta pronto a ouvir seu pronunciamento, Clitemnestra atende, dizendo: "Desejo que do seio maternal da noite | Desponte cheio de venturas este dia”. (ÉSQUILO, 1990, p. 28, grifo nosso) Ésquilo, então, nos dá uma visão positiva da escuridão, uma qualidade que remete ao conforto do enlace materno. Ou, como adiante declara o Coro, a noite é amiga, aliada, pois acoberta a ação violenta, no ataque à Troia. Importa, finalmente, salientar: qualquer que tenha sido a configuração do festival no qual Ésquilo tomou parte com Agamêmnon, o espetáculo começou sob a luz do sol, o que reforça a abordagem das relações entre poesia trágica, luz e atmosfera.

Além das qualidades da sua obra, da introdução de um segundo ator, Mynniscus de Chalci - depois de já haver trazido Cleander - o vigor da poesia de Ésquilo estabeleceu poder a uma estrutura simples, concentrada na grandeza e 
elevação heroica das personagens, criando mudanças no modelo trágico e introduzindo aspectos visuais importantes: elementos cenográficos que incluíam pinturas, altares, cenotécnica, com grande contribuição para aquela espetacularidade, o que reitera sua postura de artista familiarizado com a cena.

É importante lembrar que Ésquilo desconhecia a necessidade de luz artificial para promover visibilidade efetiva ao seu espetáculo. Ela poderia sugerir ou indicar trevas que poderiam ser, naquele momento, apenas imaginadas. Tal assertiva alcança relevância no presente estudo uma vez que o provável uso de tochas, lanternas, ou até mesmo o farol mencionado por Pollux não atenderia à função de iluminar um espaço cênico profusamente invadido pela luz do sol.

Pode-se apreender que, ao escrever com o olhar na cena, pensando em uma práxis que ocorreria durante o dia, Ésquilo operou o texto, de modo a provocar no espectador relações com a atmosfera da cena propriamente dita, o ambiente da ação a ser mimetizada e construída através da interação com o seu imaginário. Se, por um lado, o papel da luz artificial no contexto era bastante limitado, por outro, podia alcançar grande força simbólica. Profundamente envolvido com o teatro do seu tempo, Ésquilo investiu em tais possibilidades.

Contemplando a imensidão do Teatro Dionisus, em Atenas, pode-se avaliar a ousadia e o risco de uma dramaturgia exemplar, que buscava efetivar luz através da palavra, numa relação de troca, cumplicidade e compreensão do alcance das relações entre as imagens arbitrárias tanto aquelas mentais, quanto as imagens visuais. Ésquilo inaugurou, então, uma trilha seguida por outros dramaturgos, que por isso mesmo representam elevado interesse para a presente investigação.

As assertivas visuais inscritas na poesia trágica indicam a presença de feições da luz na sua constituição, estabelecendo uma provocação que revelará a cena, notadamente quando o autor considera as particularidades do opsis. Como já foi acentuado, antes de propor "textocentrismo", tal relação leva em consideração as parcerias que caracterizam a práxis cênica. Uma vez que a corporificação da cena se efetiva no espaço teatral, o dramaturgo tem a liberdade de construir sua obra em estreita cumplicidade com a luz. Aristóteles (1951, p. 124), no capítulo XXVI da Poética, concluindo suas considerações, afirma: "Mas a tragédia é superior porque contém todos os elementos da epopeia (chega até a servir-se do metro épico) e, demais, que não é pouco, a música e o espetáculo cênico [opsis], que lhe acrescem a intensidade dos prazeres que lhe são próprios."

A despeito de questionamentos acerca dessa tradução interessa aqui assinalar a possibilidade vislumbrada pelo tradutor em questão, acentuando a compreensão aristotélica da relevância da música e do opsis, considerando que Aristóteles 
tenha indicado uma distinção entre eles. Ainda que Aristóteles tenha elaborado essas considerações a certa distância temporal, uma vez que sua obra foi produzida no século IV a.c., de um ponto de vista teórico e como observador externo, a Poética alcançou status de documento chave para as reflexões acerca do teatro grego.

Ademais, vale repetir o interesse da presente abordagem na parceria entre os diversos aspectos da cena, excluindo-se quaisquer hegemonias. Reafirma-se, portanto, a poesia dramática como gênese e poderosa provocação para a corporificação cênica, como um conjunto de contribuições indissociáveis, desempenhadas por diversos artistas, questionando a inclusão de hedusmas - se eles forem compreendidos como ornamentos inconsequentes ou exagero. Por fim, a classificação de "ornamento" pode ser discutida, uma vez que todo elemento incorporado organicamente à cena torna-se teor intrínseco da sua constituição.

Quando Gazoni (2006) apresenta a possibilidade da tradução de hedusma como "tempero", ele abre um caminho promissor porque tal tempero pode se tornar item indispensável, ao contribuir para a sugestão de aromas, texturas, temperaturas, criando a atmosfera exigida pela cena. Tudo isso leva a uma premissa que indica posição particular para a luz no conjunto de contribuições como um elemento de grande fluidez e, simultaneamente, capaz de promover intervenções de grande contundência: imprescindível em certos aspectos e insubstituível em outros. Apesar da sua impalpabilidade, ela desempenha papel decisivo e único na corporificação da cena, mesmo quando pareceria não ser necessária, como na cena aberta da trilogia de Ésquilo. A poesia trágica, assim como o drama, cumpre seu destino na cena.

Como foi dito na abertura deste capítulo, além do trato político presente, tanto no teatro de Shakespeare quanto no de Ésquilo, a familiaridade com o teatro de seu tempo os levava a escrever com o olhar na cena, o que exercia uma tentação definitiva para seus impulsos poéticos. Em ambos os casos, pode-se presumir o uso de luz artificial, inclusive para sugerir noite e/ou escuridão, como um passo estratégico e orgânico da dinâmica dramatúrgica. 